\title{
Regional Differences in Opioid Prescribing in Germany - Results of an Analysis of Health Insurance Data of 57 Million Adult People
}

This article was published in the following Dove Press journal: Journal of Pain Research

\author{
Kathrin Jobski \\ Michael Dörks' \\ Carsten Bantel $^{2}$ \\ Falk Hoffmann (iD) \\ 'Department of Health Services \\ Research, Carl von Ossietzky University \\ Oldenburg, Oldenburg, Germany; \\ ${ }^{2}$ University Department of \\ Anesthesiology, Critical Care, Emergency \\ and Pain Medicine, Klinikum Oldenburg, \\ Oldenburg, Germany
}

Background: Regional variations of opioid use have been reported from many countries. The objective of this study was to examine opioid prescribing patterns in Germany including low- and high-potency opioids (LPO and HPO) focusing on regional differences.

Methods: Data source was the "Information system for health care data" comprising statutory health insurance funds data for about 70 million Germans of all ages. For 2010, we received aggregated data (by age, sex, federal state and district) of Germans (18+) who had been prescribed at least one opioid including the number of prescribed packages. For each stratum, we further received the number of insured persons. We calculated LPO and HPO prevalences and the mean number of prescribed packages.

Results: Among 57 million adult Germans (mean age: 50.2 years, 53.8\% female), opioid prevalences were 38.7 per 1000 persons for LPOs and 12.8 for HPOs. Prevalences rose with increasing age and were higher in women than in men. On average, LPO users were prescribed fewer packages than HPO users (3.5 vs 7.0). LPO use was highest in the eastern states ranging from 32.9 per 1000 persons (Hamburg) to 47.2 (Saxony-Anhalt). HPOs were most often prescribed in the North and in the East with prevalences varying between 10.6 per 1000 persons (Baden-Württemberg) and 16.9 (Mecklenburg-Western Pomerania). On the district level, prevalences varied by the factors 2.6 and 3.2 for LPOs and HPOs, respectively. Conclusion: We found large regional variations in opioid prescribing which probably cannot only be attributed to differences in patient characteristics.

Keywords: opioids, prescribing patterns, prevalence, regional variations, Germany

\section{Introduction}

Opioids are essential drugs in the treatment of acute and chronic pain conditions. ${ }^{1-3}$ Over the last decades, rising opioid use has been reported especially for chronic non-cancer pain conditions ${ }^{4,5}$ although in these indications opioid treatment was only associated with small improvements compared with placebo according to a recent meta-analysis. ${ }^{6}$ Since the 1990 s, opioid use increased substantially in North America but also in Europe including Germany., ${ }^{4,8}$ The largest rise of opioid prescriptions has been observed in the US where overprescribing led to a sharp increase in the prevalence of opioid addiction, which in turn has been associated with rising numbers of overdose deaths and heroin use. ${ }^{9-12}$ A systematic review analyzing problematic opioid use in adults with chronic pain using oral opioids, found that opioid misuse averaged between $21 \%$ and $29 \%{ }^{13}$ A German crosssectional study recently reported a similar proportion of opioid use disorder
Correspondence: Kathrin Jobsk

Department of Health Services Research, Carl von Ossietzky University Oldenburg,

Ammerländer Heerstr I |4- I 18,

Oldenburg 26129, Germany

Tel +49 44I - 7982330

Fax $+4944 I-7985824$

Email kathrin.jobski@uni-oldenburg.de
Journal of Pain Research 2020:13 2483-2492

2483

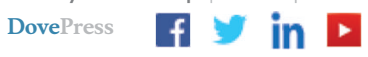

(c) (i) (5) 2020 Jobski et al. This work is published and licensed by Dove Medical Press Limited. The full terms of this license are available at https://www.dovepress.com/terms. cc) BY work you hereby accept the Terms. Non-commercial uses of the work are permitted without any further permission from Dove Medical Press Limited, provided the work is properly attributed. For permission for commercial use of this work, please see paragraphs 4.2 and 5 of our Terms (https://www.dovepress.com/terms.php). 
(26.5\%) in adult patients with chronic non-cancer pain receiving long-term opioid therapy. ${ }^{14}$

Opioid use varies widely between different countries. According to the United Nations' International Narcotics Control Board the 5 highest ranking countries with respect to the levels of per capita consumption of opioids in the years 2015 to 2017 were the United States, Germany, Canada, Austria and Belgium ${ }^{15}$ with values varying by the factor 2. For Europe a more than 10-fold difference was observed between the highest consumption in Western/Northern countries and the lowest in Southern/ Eastern countries. $^{7}$

Besides differences between countries, regional variations in opioid utilization are known for example from the United States, the United Kingdom or Australia ${ }^{8,16-19}$ listing, among others, ruralness and lower social economic status as influencing factors for higher opioid consumption.

For Germany, a recent systematic review found that opioid use was more common in the north. ${ }^{5}$ Regional analyses, however, so far were based on data from one statutory health insurance (SHI) provider and presented data only for high-potency opioids. ${ }^{20}$ Further, potential differences with respect to the ruralness of a person's residential area were not examined.

Therefore, the aim of our study was to analyze opioid use in Germany on a regional level using a large database including all adults insured with an SHI.

\section{Methods}

\section{Data Source}

Data were retrieved from the "Health Care Data Information System", located at the German Institute of Medical Documentation and Information (DIMDI) ${ }^{21}$ which includes data from about 70 million persons insured with an SHI ( $85 \%$ of the German population). The SHIs deliver data to the German Federal Insurance Authority (BVA) to be used for the calculation of the morbidityoriented risk structure compensation scheme (MorbiRSA). Since 2014 the BVA transfers data to the DIMDI which, on application, provides anonymized aggregated data for research purposes for entitled users.

For this project we used data from 2010 which, at the time of application, was the most recent year to provide information also on a regional level including federal states and districts. The latter were allocated to the current districts $(n=402)$ accounting for the changes in counties in
Mecklenburg-Western Pomerania. ${ }^{22}$ Accordingly, Germany's 16 federal states include between $n=1$ (Hamburg, Berlin) and $\mathrm{n}=96$ (Bavaria) districts.

We used data for all persons insured with an SHI for at least 180 days in 2010 and who were 18 years or older in the respective year. On a state level, the number of all insured persons was provided by age group (18-29, 30-49, 50-69 and $\geq 70$ years) and sex whereas on the district level only the overall numbers, the mean age and sex ratio per district were available.

Opioids were classified as low- and high-potency opioids (LPO and HPO, steps 2 and 3 of the World Health Organization's analgesic ladder, respectively). As defined by the German Narcotic Drugs Act (2010 version) the following anatomical chemical therapeutic (ATC) codes were included as LPO: N02AA08, N02AX02, N02AX52, N02AX51 (excluding codeine) with a focus on tramadol (N02AX02, N02AX52) and tilidine/naloxone (N02AX51). Among HPOs (N02AA01, N02AE01, N02AB03, N02AA55, N02AA05, N02AA03, N02AC06, N02AC03, $\mathrm{N} 02 \mathrm{AB} 02, \mathrm{~N} 02 \mathrm{AX} 06$ ) the mainly used agents in Germany, namely fentanyl (N02AB03), morphine (N02AA01), oxycodone (N02AA05), oxycodone/naloxone (N02AA55) and hydromorphone (N02AA03) ${ }^{23}$ were of special interest.

Opioid users were defined as all persons with at least one opioid prescription in 2010. On the federal state level, we received the number of opioid users as well as the number of prescribed opioid packages by age group and sex whereas on a district level only the overall numbers (users and packages) were available.

We applied for the data on 29 Feb 2016 by submitting a study proposal and an SQL analysis script. After intensive reviewing and changes made by the DIMDI, we received the final and, as described above, highly aggregated dataset on 19 Dec 2018.

\section{Statistical Analyses}

Employing descriptive analyses, we calculated LPO and HPO use per 1000 persons and the mean number of packages prescribed per user stratified by age and sex as well as on federal state and district levels. Use of the most common agents was only displayed on federal state level.

Additionally, LPO and HPO prevalences were standardized by age and sex using the overall population as standard population.

To characterize the type of district we used the 2010 location indicator of the Federal Institute for Research on Building, Urban Affairs and Spatial Development (BBSR). 
This indicator classifies the geographical position of each district as highly central $(n=106)$, central $(n=145)$, peripheral $(n=133)$ and highly peripheral $(n=18)$ based on its population during the daytime (including commuters) and thereby accounting for the proximity and accessibility to, among others, jobs and health care. ${ }^{24}$ According to this classification, peripheral districts cover large parts of the rural area, whereas highly peripheral districts are sparsely populated areas, eg in Mecklenburg-Western Pomerania, Brandenburg, Saxony-Anhalt but also in the eastern parts of Bavaria and along the North Sea coast. ${ }^{25}$

For all statistical analyses, of the highly aggregated data received, and the creation of maps we used SAS version 9.4 (SAS Institute Inc, Cary, North Carolina). All figures shown were specifically prepared for this article.

\section{Results}

\section{Characteristics of the Study Population, Opioid Use by Age Group and Sex}

Data from 57,359,702 persons $\geq 18$ years were analyzed. Their mean age was 50.2 years, $53.8 \%$ were female and $24.6 \%$ lived in peripheral areas. Mean age ranged from 48.3 in Hamburg to 52.7 years in Saxony-Anhalt and the proportion of females from $52.9 \%$ (Thuringia) to $54.6 \%$ (Schleswig-Holstein). Persons living in highly central districts were somewhat younger (mean age 49.6 years) and slightly more often female (54.1\%) compared to those living in other areas (eg 52.1 years and $53.1 \%$ female in districts classified as highly peripheral).

The overall prevalence of opioid use was 38.7 per 1000 persons for LPOs and 12.8 per 1000 persons for HPOs (Table 1). Prevalences rose with increasing age and were higher in women than in men. While prevalences differed only slightly in the younger age groups between sexes, they were substantially higher in women aged 70 years or older compared with men of the same age group (103.6 vs 68.0 for LPOs and 49.0 vs 25.1 per 1000 persons for HPOs). On average, LPO users were prescribed 3.5 packages whereas HPO users received a mean of 7.0 packages with virtually no differences between sexes.

\section{Regional Variation of LPO Use}

Overall, LPO use was higher in the eastern parts of Germany than in western states. Prevalence ranged from 32.9 per 1000 persons in Hamburg to 47.2 in SaxonyAnhalt with the lowest prevalence found in GarmischPartenkirchen (Bavaria, 23.2) and the highest in Osterode am Harz (Lower Saxony, 59.7; Table 2 and Supplemental Figure 1). Standardization by age and sex showed slightly different prevalences but an overall similar picture (Figure 1). With respect to the type of district, prevalences ranged from 37.4 in highly central districts to 45.2 in areas classified as highly peripheral. These differences could also be observed when comparing districts with similar mean ages (Supplemental Figure 2).

Users from Bavaria received the lowest number of mean packs (3.3) and those living in Bremen the highest number (3.8). Tramadol was the most commonly used LPO (23.1 users per 1000 persons, mean packs per user: 3.0, 50.4\% of all prescribed LPO packages; Table 3 and Supplemental Figure 3) except in Baden-Württemberg, Saarland and Saxony where tilidine was used more often. The largest difference between the prevalence of tramadol and tilidine use was found in Schleswig Holstein (28.5 vs 10.4 per 1000 persons).

The percentage of LPO packs among all opioid (LPO and HPO) packs ranged from 53.9 (Schleswig-Holstein) to $64.4 \%$ in Baden-Württemberg (Germany: 60.5\%). On

Table I Opioid Use in Germany by Age Group and Sex in 2010

\begin{tabular}{|c|c|c|c|c|c|c|c|c|c|c|c|c|}
\hline & \multicolumn{6}{|c|}{ Low-Potency Opioids } & \multicolumn{6}{|c|}{ High-Potency Opioids } \\
\hline & \multicolumn{3}{|c|}{ Users per 1000 Persons } & \multicolumn{3}{|c|}{ Mean Packs per User } & \multicolumn{3}{|c|}{ Users per 1000 Persons } & \multicolumn{3}{|c|}{ Mean Packs per User } \\
\hline & All & Male & Female & All & Male & Female & All & Male & Female & All & Male & Female \\
\hline \multicolumn{13}{|l|}{ Age group } \\
\hline $18-29$ years & 6.4 & 5.9 & 6.9 & 2.2 & 2.3 & 2.1 & 0.5 & 0.5 & 0.5 & 6.6 & 7.0 & 6.2 \\
\hline $30-49$ years & 20.1 & 19.5 & 20.6 & 3.1 & 3.1 & 3.1 & 3.5 & 3.2 & 3.8 & 8.6 & 8.6 & 8.7 \\
\hline $50-69$ years & 45.0 & 40.8 & 48.7 & 3.5 & 3.6 & 3.5 & 12.9 & 11.8 & 13.9 & 7.3 & 7.5 & 7.2 \\
\hline$\geq 70$ years & 89.7 & 68.0 & 103.6 & 3.8 & 3.6 & 3.9 & 39.7 & 25.1 & 49.0 & 6.6 & 6.3 & 6.6 \\
\hline Overall & 38.7 & 31.4 & 44.9 & 3.5 & 3.5 & 3.6 & 12.8 & 8.9 & 16.2 & 7.0 & 7.1 & 6.9 \\
\hline
\end{tabular}




\begin{tabular}{|c|c|c|c|c|c|c|c|}
\hline \multirow{3}{*}{ 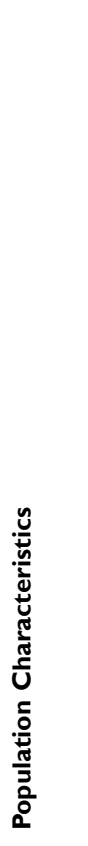 } & 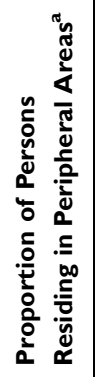 & 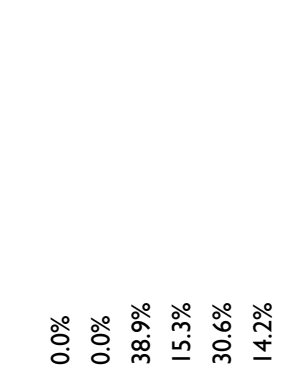 & 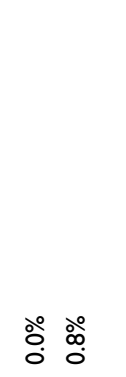 & 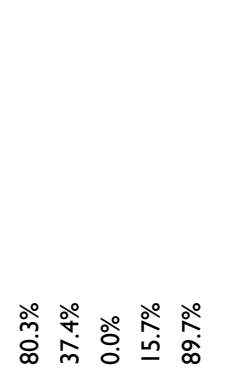 & 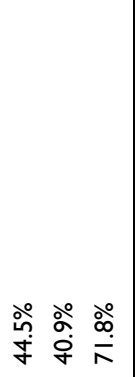 & 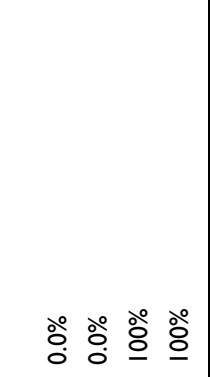 & $\begin{array}{l}\stackrel{\circ}{\circ} \\
\stackrel{\sim}{\sim}\end{array}$ \\
\hline & 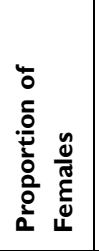 & 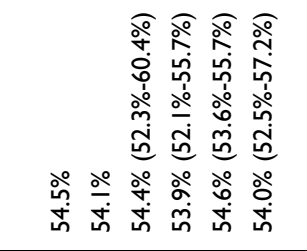 & 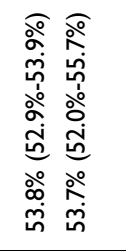 & 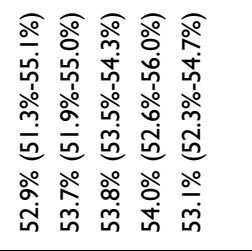 & 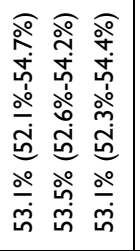 & 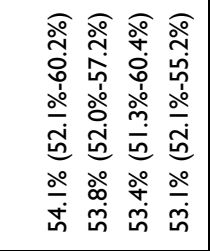 & 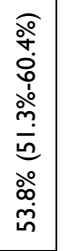 \\
\hline & 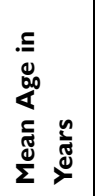 & 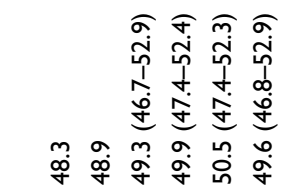 & 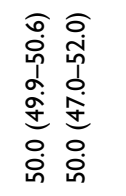 & 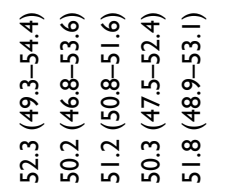 & 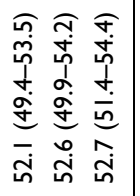 & 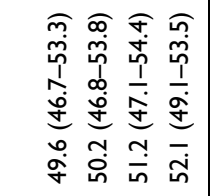 & 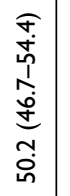 \\
\hline 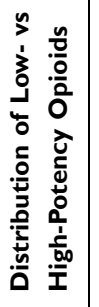 & 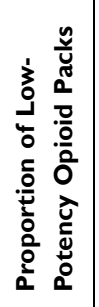 & 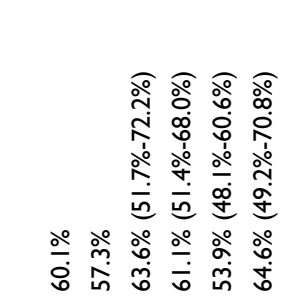 & 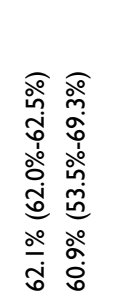 & 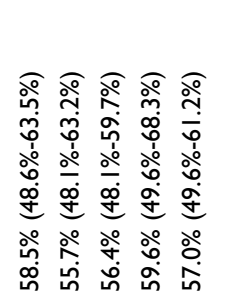 & 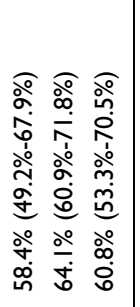 & 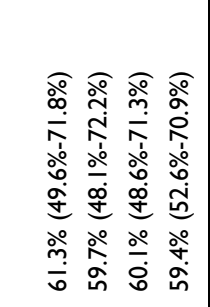 & 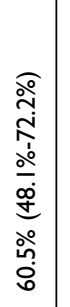 \\
\hline \multirow{2}{*}{ 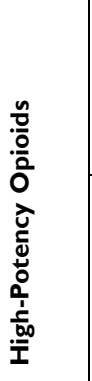 } & 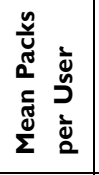 & 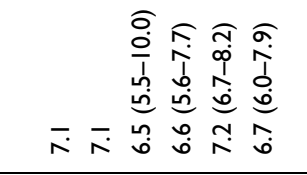 & 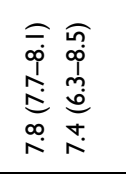 & 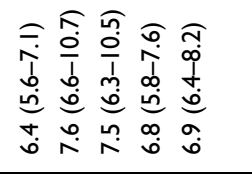 & 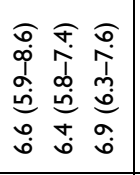 & 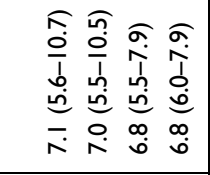 & 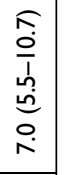 \\
\hline & 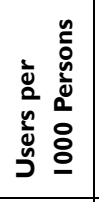 & 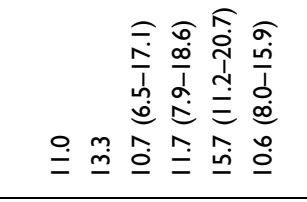 & 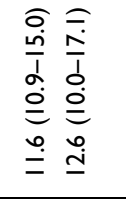 & 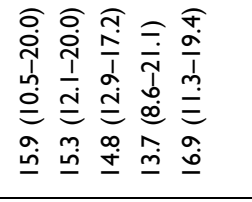 & 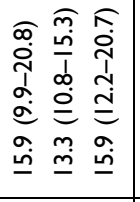 & 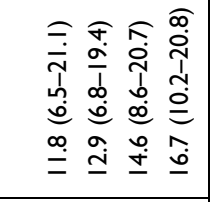 & 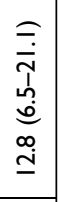 \\
\hline \multirow{2}{*}{ 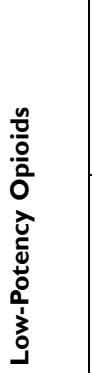 } & 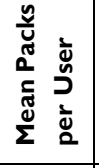 & 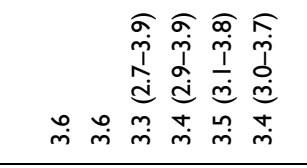 & 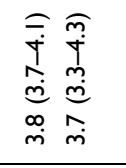 & 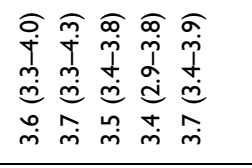 & 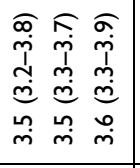 & 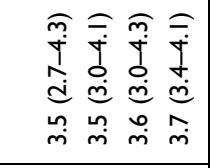 & 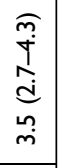 \\
\hline & 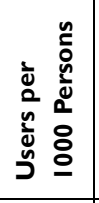 & 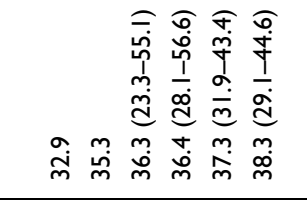 & 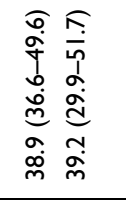 & 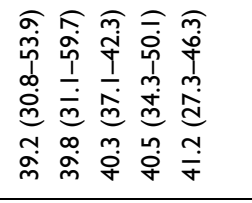 & 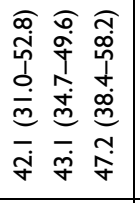 & 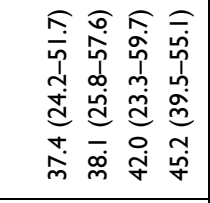 & 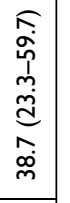 \\
\hline \multicolumn{2}{|l|}{ 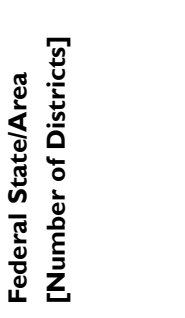 } & \multicolumn{4}{|c|}{ 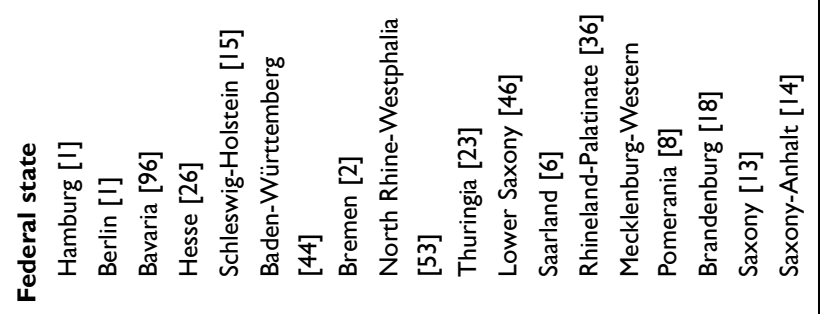 } & 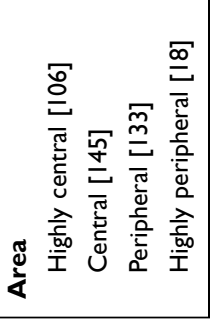 & 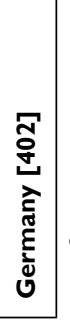 \\
\hline
\end{tabular}


a district level, the lowest value was observed in Steinburg, Schleswig-Holstein (48.1\%) and the highest in Schweinfurt, Bavaria (72.2\%).

\section{Regional Variation of HPO Use}

Overall, HPO use was highest in the North and in the East of Germany. Prevalence was lowest in BadenWürttemberg (10.6 per 1000 persons) and highest in Mecklenburg-Western Pomerania (16.9; Table 2 and Supplemental Figure 1). Similar results were found after standardizing prevalence by age and sex (Figure 1). On a district level the lowest prevalence was observed in Munich, Bavaria (6.5 per 1000 persons) and the highest in Speyer, Rhineland-Palatinate (21.1). In highly central districts HPO use was lower than in those classified as highly peripheral (11.8 vs 16.7 per 1000 persons; Table 2).

Users from Saxony and Thuringia received the lowest number of mean packs (6.4) and those living in Bremen the highest number (7.8; Table 2). Fentanyl was the most often used HPO (4.5 users per 1000 persons, 32.5\% of all prescribed HPO packages), except in Saarland and Bremen where oxycodone/naloxone (5.5) and morphine (4.5 per 1000 persons) were the most commonly used agents, respectively (Table 3). Overall, the mean number of packs was highest for morphine (7.1), followed by fentanyl (6.4) and lowest for oxycodone/naloxone (4.4).

\section{Discussion and Conclusion Key Findings}

In the present study including all adult Germans insured with an SHI in 2010, we found that opioid prescribing varied widely across federal states and districts. Overall, 1 in 25 persons was prescribed at least one LPO and 1 in 78 received HPO treatment. On the federal state level, the ratio of the highest and the lowest prevalence was 1.4 for LPOs and 1.6 for HPOs whereas, on a district level, higher ratios were observed (2.6 and 3.2 for LPOs and HPOs, respectively). Interestingly, in 4 federal states (Hamburg, Hesse, Bavaria and Baden-Württemberg) LPO and HPO prevalences were lower than or equal to the respective national prevalences, whereas in 8 states (Lower Saxony, Rhineland-Palatinate, Saarland and the five eastern states except Berlin) both prevalences exceeded the nation-wide values.

The degree of variation found in this study is similar to other countries. A study from the United States for instance found prescriptions of opioids per 100 persons on a state level varied 2.7 -fold. ${ }^{26}$ In the UK, opioid use was somewhat higher in the North compared with the South (factor 1.5). ${ }^{27}$ An Australian study reported that the number of packs of prescription opioids per person varied by the factor 3 in the different regions. ${ }^{19}$

\section{Substances of Choice and Number of Packages}

Overall, LPOs were prescribed more often than HPOs which is plausible since the former are not regulated by the Narcotic Drugs Prescription Ordinance which, among others, requires special prescription forms. Nevertheless, the high prevalence of tramadol use was surprising as it is often thought to be associated with a higher risk of falls compared to other opioids such as morphine, oxycodone and fentanyl ${ }^{28}$ and with an increased risk of delirium in the elderly. ${ }^{29}$ However, since these analyses are solely based on prescriptions reimbursed by the SHIs, an underestimation of the use of tilidine, an opioid mainly used in Germany, ${ }^{15}$ cannot be ruled out, since before 2013, especially liquid formulations were often obtained on private prescriptions. $^{30}$

Fentanyl has been the most commonly used HPO in Germany for years ${ }^{5,20,31}$ which is reflected here by the high prescription prevalence and the finding that nearly every third HPO package was fentanyl. This is in contrast to other countries were other HPO substances are far more prominent (eg oxycodone in the US or Australia). ${ }^{7,19,32}$

The mean number of packages was about twice as high in HPO compared to LPO users which probably mirrors the severity or duration of the underlying disease but also suggests that LPOs were either used for a shorter time period eg following an operation, or that patients were switched from or (more likely) to an HPO.

\section{Potential Reasons for Regional Variations}

When exploring reasons for regional variations of opioid use, several factors come into play including (a) patients' characteristics such as demographics or burden of pain, (b) physicians' attitude or schools of thinking with respect to opioids but also (c) the health care system including access to specialized care, availability of services and the possibility of reimbursement for alternative treatments. ${ }^{33}$ In contrast to the US where for instance prescription drug monitoring programs can be regulated via state-level policies and thereby contribute to regional variations of opioid 

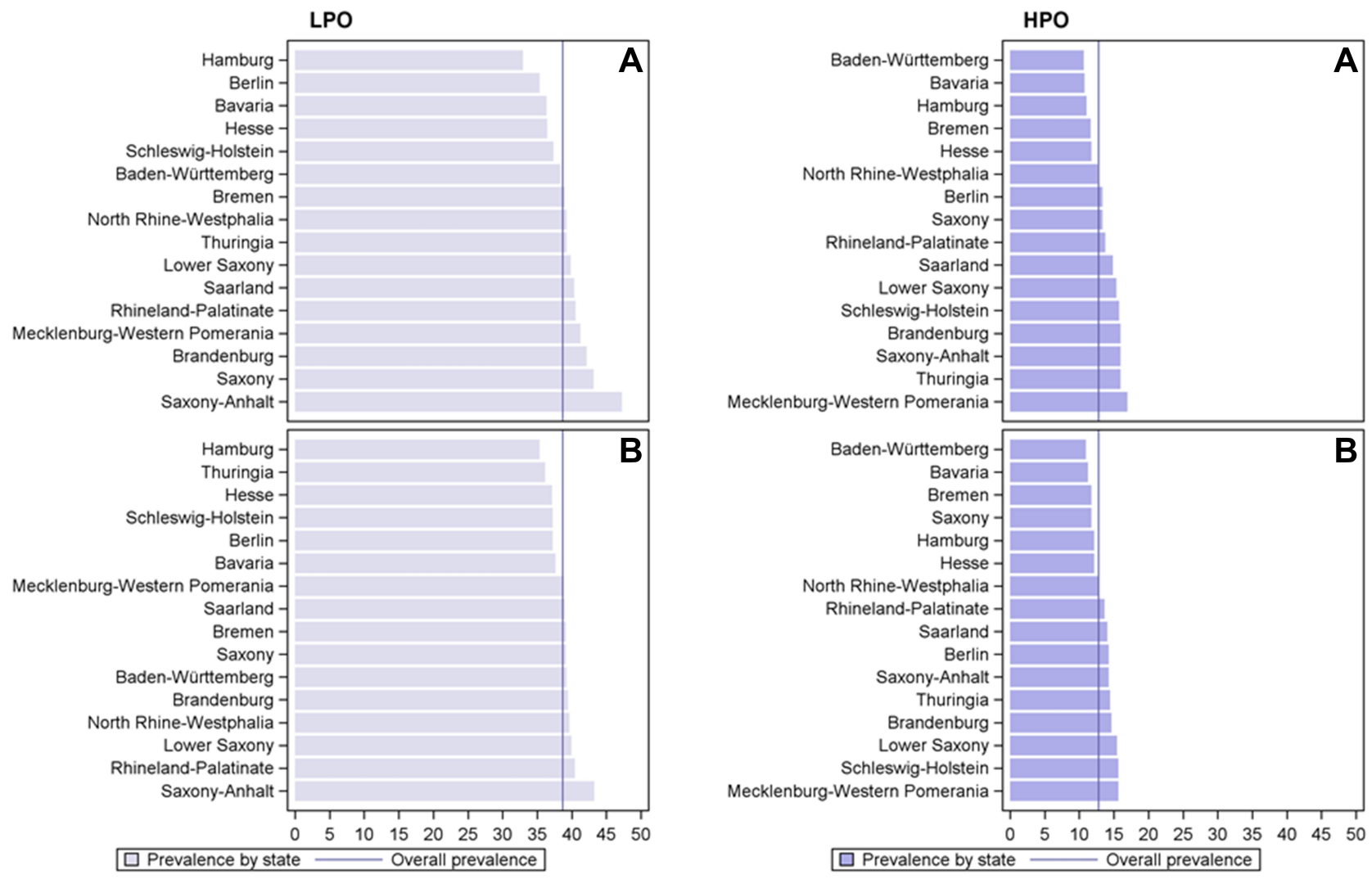

Figure I LPO and HPO users per 1000 persons by state (A: raw prevalence, B: standardized by age and sex).

Abbreviations: HPO, high-potency opioid; LPO, low-potency opioid.

use, opioid prescribing and dispensing in Germany is subject to national regulations.

Regarding patients' characteristics, we found that opioid use is highly associated with rising age and female sex which is in line with studies examining pain prevalences in Germany. ${ }^{34,35}$ Therefore, it seems plausible that federal states and districts with an older population and a higher proportion of females display higher opioid prevalences. This could be observed for LPO prescriptions where higher prevalences were found in states with a higher median population age whereas for HPOs the pattern was less clear. Accordingly, no obvious tendencies could be found with respect to opioid use and sex on a state level. Standardizing opioid prevalences by age and sex showed slightly different prevalences but an overall similar picture. Therefore, the observed regional variations probably cannot only be attributed to the differences in demographic characteristics.

We found that federal states with opioid prevalences above the nation-wide values were mainly characterized by a large proportion of inhabitants residing in peripheral districts and that persons living in more peripheral areas had higher opioid prevalences than their centrally residing counterparts also when comparing districts with a similar median age. This is in line with other studies. ${ }^{16,27}$ Therefore, one might assume that in areas where people have less access to specialized care such as pain or palliative care services or where fewer alternatives such as physiotherapy are available, physicians are more likely to prescribe pain medication to meet the patients' needs. This might be supported by regional variations of the residents' socioeconomic status, which was shown to have an influence on opioid use in international studies. ${ }^{17,36,37}$ In Germany, districts categorized as peripheral or very peripheral, ${ }^{24}$ where opioid use was high, largely overlap with areas displaying lower socioeconomic indicators (measured by education, occupation and income). These areas are, for example, located in Saarland, North RhineWestphalia, in rural areas of Lower Saxony and in the east of Germany. ${ }^{37}$ In accordance with the overall east-west divide of opioid prevalences observed in this study, further a higher burden of pain, which has also been associated 


\begin{tabular}{|c|c|c|c|c|c|c|c|c|}
\hline \multirow{2}{*}{ 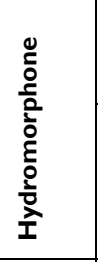 } & 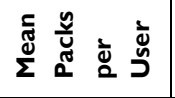 & 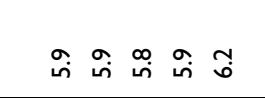 & $\stackrel{\circ}{\circ}$ & $\hat{n}$ & ஸ் & $\stackrel{\infty}{n}$ & นุ & $\stackrel{0}{0}$ \\
\hline & 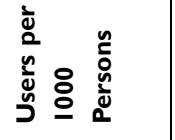 & 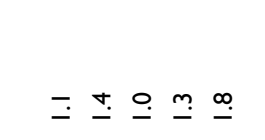 & $=$ & $\Xi \stackrel{m}{=}$ & $\bar{i} \underline{a} \stackrel{a}{-} \stackrel{0}{-}$ & $\dot{\sim}$ & 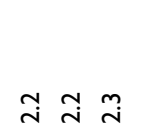 & $\underline{\underline{n}}$ \\
\hline \multirow[b]{2}{*}{ 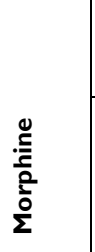 } & 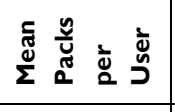 & 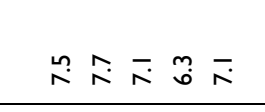 & $\stackrel{t}{6}$ & $\stackrel{\infty}{\wedge} \stackrel{m}{\wedge}$ & 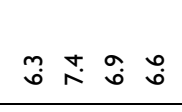 & $\stackrel{\infty}{\circ}$ & $\stackrel{m}{\wedge} \stackrel{0}{\infty} \bar{\infty}$ & $\bar{r}$ \\
\hline & 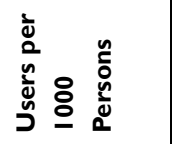 & $\stackrel{m}{m} \stackrel{\infty}{i} \stackrel{+}{\leftrightarrows} \stackrel{\circ}{i} \stackrel{\sigma}{\sim}$ & $\underline{a}$ & $\stackrel{\operatorname{Ln}}{+} \stackrel{i}{i}$ & $\stackrel{\check{I}}{\dot{m}} \stackrel{\grave{i}}{\bar{N}}$ & $\stackrel{\circ}{i}$ & $\stackrel{\infty}{-}$ 우 & $\stackrel{\sim}{\mathrm{N}}$ \\
\hline \multirow[b]{2}{*}{ 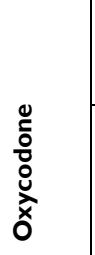 } & 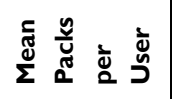 & 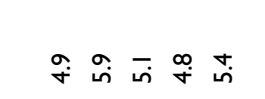 & $\bar{n}$ & $\stackrel{0}{\circ} \stackrel{\infty}{\infty}$ & m. & $\stackrel{\infty}{n}$ & 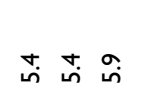 & $\stackrel{\llcorner\cap}{n}$ \\
\hline & 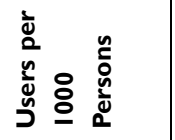 & 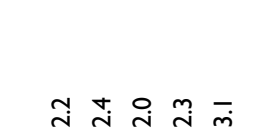 & ส & $\stackrel{\circ}{i}$ & $\stackrel{n}{i} \stackrel{\infty}{i} \stackrel{\circ}{i} \stackrel{m}{i}$ & $\stackrel{\circ}{i}$ & $\hat{i} \stackrel{m}{m} \stackrel{i}{i}$ & $\stackrel{m}{i}$ \\
\hline \multirow[b]{2}{*}{ 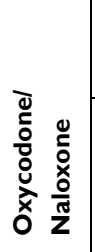 } & 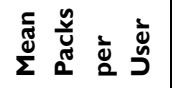 & 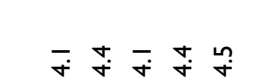 & $\stackrel{m}{*}$ & 广ீ & 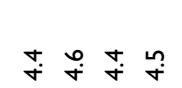 & $\stackrel{+}{+}$ & $\stackrel{+}{x} \hat{f}$ & $\stackrel{+}{\dot{*}}$ \\
\hline & 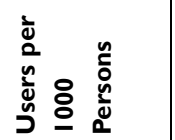 & 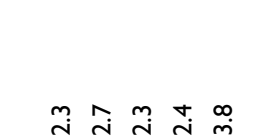 & $\stackrel{ \pm}{i}$ & $\stackrel{\text { i̊ }}{\stackrel{L}{N}}$ & $\hat{m} \stackrel{m}{m}$ 望 & $\stackrel{m}{m}$ & 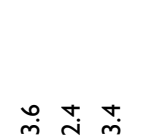 & $\stackrel{\infty}{i}$ \\
\hline \multirow[b]{2}{*}{ 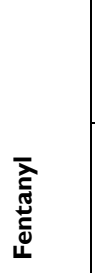 } & 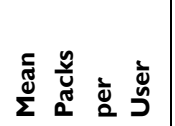 & 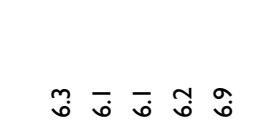 & ชี & $\hat{\omega} \stackrel{\infty}{\infty}$ & mె 웅 & $\stackrel{t}{b}$ & $\bar{\omega} \overline{0}$ น & $\stackrel{+}{6}$ \\
\hline & 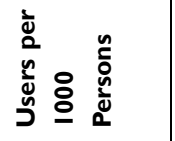 & 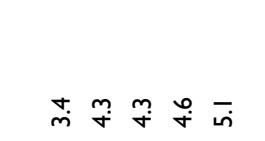 & $\stackrel{\circ}{m}$ & $\stackrel{m}{m} \stackrel{\llcorner}{+}$ & ウ̆ & மீ & 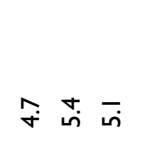 & $\stackrel{\sim}{+}$ \\
\hline \multirow{2}{*}{ 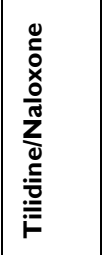 } & 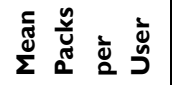 & 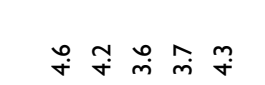 & $\stackrel{n}{m}$ & $\stackrel{\sim}{\sim} \underset{\dot{m}}{\sigma}$ & $\stackrel{\sigma}{\dot{m}} \stackrel{\circ}{+} \hat{m} \stackrel{0}{\dot{m}}$ & $\stackrel{\sigma}{\dot{m}}$ & $\stackrel{\sigma}{\dot{m}} \stackrel{0}{\dot{m}} \underset{m}{\infty}$ & $\stackrel{\infty}{m}$ \\
\hline & 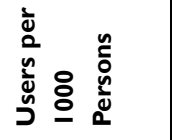 & 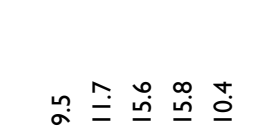 & $\hat{n}$ & $\stackrel{\sigma}{\underline{m}} \stackrel{m}{\underline{a}}$ & $\stackrel{m}{a} \underline{\underline{0}} \overline{\bar{N}} \overline{\bar{N}}$ & $\stackrel{2}{\infty}$ & 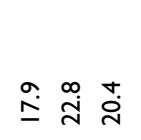 & 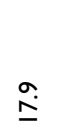 \\
\hline \multirow[b]{2}{*}{ 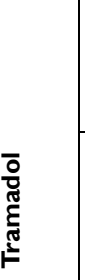 } & 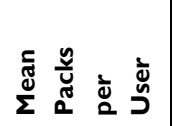 & 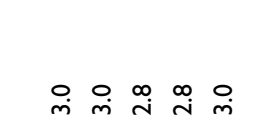 & $\hat{i}$ & $\stackrel{m}{m} \bar{m}$ & $\bar{m} \bar{m} \stackrel{\sigma}{\stackrel{\infty}{i}}$ & $\stackrel{m}{m}$ & 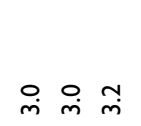 & $\stackrel{\circ}{m}$ \\
\hline & 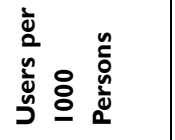 & 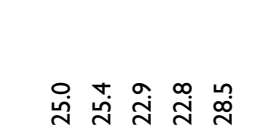 & $\stackrel{a}{\infty}$ & 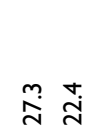 & 宗岕 & $\stackrel{a}{\dot{d}}$ & 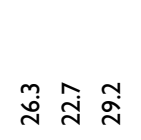 & $\overline{\dot{\sim}}$ \\
\hline & \multicolumn{6}{|c|}{ 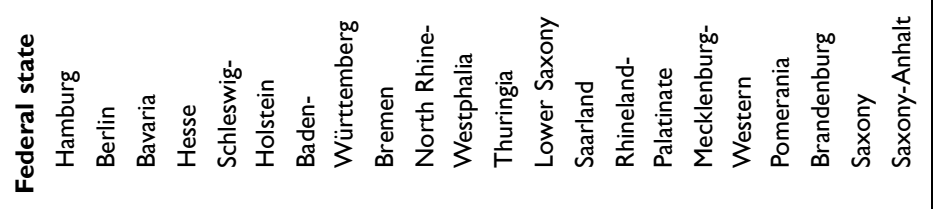 } & 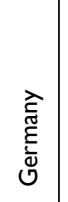 \\
\hline
\end{tabular}


with a lower socioeconomic status, ${ }^{35}$ has been reported from the eastern compared with the western federal states. $^{38,39}$

On the other hand, physiotherapy as an alternative treatment, is traditionally more often prescribed in the eastern federal states including Berlin than in western Germany ${ }^{40,41}$ suggesting that, at least on the population level, physiotherapy is not used as a non-pharmacological alternative for opioids. Therefore, probably other prescriber-related factors come into play, especially as we also found differences between the north and the south of Germany for LPO and HPO prescribing. These observed large differences might for example indicate deviating schools of thought about opioids. Finally, differences might be attributed to physicians' characteristics such as age, specialty and education which are probably associated with the type and location of their practice and also their clients. Interestingly, findings from a recent US study suggest the medical school, where the prescribing physicians completed their initial training, has a large impact on their attitudes towards opioid prescribing, even within the same specialty and practice location. ${ }^{42}$

The finding here that in 12 of the 16 federal states, LPO as well as HPO prevalences were either comparatively high or low, further suggests that prescriber preferences concern opioids in general and that lower LPO prescribing is not compensated by higher use of HPOs and vice versa.

\section{Strengths and Limitations}

The major strength of the present study was the size of the database covering all persons insured with an SHI making it the largest study on opioid use in Germany. Our results can be considered unbiased, since the differences observed between persons insured with different SHI providers with respect eg to demographics, socio-economic status and morbidity $^{43,44}$ do not limit the generalizability of the results. Based on the large sample size, the data additionally allowed analyses on a district level therefore providing stable numbers on opioid use on a smaller scale.

A major drawback is that the data are from 2010, which at the time of application was the most recent year providing information also on a district level. Further, the dataset we received was highly aggregated: Data on a substance level were only available for individual federal states but not districts precluding further analyses of potential compensation mechanisms on district level. With respect to demographics, the dataset included fewer age groups than we had originally applied for and for these groups no information on the number of persons residing in central or peripheral areas was available, hampering further analyses such as linear regression. On a district level, only overall numbers of users were available therefore standardization by age and sex could not be conducted on this level. Finally, the reason for opioid use such as type, intensity or duration of pain as well as opioid treatment patterns or the specialty and preferences of the prescribing physicians which might have explained regional variations could not be assessed with the present data and therefore are subject to speculation. As a consequence, these data do not allow to determine whether our results display an over- or underprescribing or even misprescribing of opioids in the respective federal states and districts.

\section{Conclusions}

In this study including all adult Germans insured with an SHI, we found large regional variations of opioid prescribing which can probably only in part be explained by sociodemographic differences. Therefore, further studies are clearly needed to examine the reasons for the differences in opioid prescribing on an individual level and focusing on patient and prescriber characteristics.

\section{Author Contributions}

All authors made substantial contributions to conception and design, acquisition of data, or analysis and interpretation of data; took part in drafting the article or revising it critically for important intellectual content; agreed to submit to the current journal; gave final approval of the version to be published; and agree to be accountable for all aspects of the work.

\section{Funding}

There is no funding to report.

\section{Disclosure}

The authors declare that they have no conflicts of interest for this work.

\section{References}

1. World Health Organization (WHO). World Health Organization Model List of Essential Medicines, 21st List; 2019.

2. Wiffen PJ, Wee B, Derry S, et al. Opioids for cancer pain - an overview of cochrane reviews. Cochrane Database Syst Rev. 2017;7: CD012592. doi:10.1002/14651858.CD012592.pub2

3. Dowell D, Haegerich TM, Chou R. CDC guideline for prescribing opioids for chronic pain-United States, 2016. JAMA. 2016;315:1624. doi:10.1001/jama.2016.1464 
4. Schubert I, Ihle P, Sabatowski R. Increase in opiate prescription in Germany between 2000 and 2010: a study based on insurance data. Dtsch Arztebl Int. 2013;110:45-51. doi:10.3238/arztebl.2013.0045

5. Rosner B, Neicun J, Yang JC, Roman-Urrestarazu A. Opioid prescription patterns in Germany and the global opioid epidemic: systematic review of available evidence. PLoS One. 2019;14(8): e0221153. doi:10.1371/journal.pone.0221153

6. Busse R, Blümel M. Germany. Health system review. European Observatory on Health Systems and Policies. Health Syst Transit. 2014;16(2).

7. Bosetti C, Santucci C, Radrezza S, et al. Trends in the consumption of opioids for the treatment of severe pain in Europe, 1990-2016. Eur J Pain. 2018. doi:10.1002/ejp.1337

8. Curtis HJ, Croker R, Walker AJ, et al. Opioid prescribing trends and geographical variation in England, 1998-2018: a retrospective database study. Lancet Psychiatry. 2019;6(2):140-150. doi:10.1016/ S2215-0366(18)30471-1

9. Paulozzi LJ, Jones CM, Mack KA, Rudd RA. Vital signs: overdoses of prescription opioid pain relievers — United States, 1999-2008. MMWR Morb Mortal Wkly Rep. 2011;60:1487-1492.

10. Fischer B, Jones W, Urbanoski K, et al. Correlations between prescription opioid analgesic dispensing levels and related mortality and morbidity in Ontario, Canada, 2005-2011. Drug Alcohol Rev. 2014;33(1):19-26. doi:10.1111/dar.12089

11. Dunn KM, Saunders KW, Rutter CM, et al. Opioid prescriptions for chronic pain and overdose: a cohort study. Ann Intern Med. 2010;152 (2):85. doi:10.7326/0003-4819-152-2-201001190-00006

12. Kolodny A, Courtwright DT, Hwang CS, et al. The prescription opioid and heroin crisis: a public health approach to an epidemic of addiction. Annu Rev Public Health. 2015;36(1):559-574. doi:10.1146/annurev-publhealth-031914-122957

13. Vowles KE, McEntee ML, Julnes PS, et al. Rates of opioid misuse, abuse, and addiction in chronic pain. Pain. 2015;156(4):569-576. doi:10.1097/01.j.pain.0000460357.01998.f1

14. Just JM, Schwerbrock F, Bleckwenn M, et al. Opioid use disorder in chronic non-cancer pain in Germany: a cross sectional study. $B M J$ Open. 2019;9:e026871. doi:10.1136/bmjopen-2018-026871

15. United Nations International Narcotics Control Board Narcotic Drugs Estimated World Requirements for 2019 Statistics for 2017. Available from: https://www.incb.org/documents/Narcotic-Drugs /Technical-Publications/2018/INCB-

Narcotics Drugs Technical Publication 2018.pdf. Accessed September 1, 2020.

16. McDonald DC, Carlson K, Izrael D. Geographic variation in opioid prescribing in the U.S. J Pain. 2012;13(10):988-996. doi:10.1016/j. jpain.2012.07.007

17. Chen TC, Chen LC, Kerry M, Knaggs RD. Prescription opioids: regional variation and socioeconomic status - evidence from primary care in England. Int J Drug Policy. 2019;64:87-94. doi:10.1016/j. drugpo.2018.10.013

18. Lund BC, Ohl ME, Hadlandsmyth K, Mosher HJ. Regional and rural-urban variation in opioid prescribing in the veterans health administration. Mil Med. 2019;184(11-12):894-900. doi:10.1093/ milmed/usz104

19. Degenhardt L, Gisev N, Cama E, et al. The extent and correlates of community-based pharmaceutical opioid utilisation in Australia. Pharmacoepidemiol Drug Saf. 2016;25(5):521-538. doi:10.1002/ pds. 3931

20. Hoffmann F, Glaeske G, Windt R. Prescription of high-potency opioids in 2011. Schmerz. 2012;26:707-714. German. doi:10.1007/ s00482-012-1240-7

21. German Institute of Medical Documentation and Information (DIMDI) Information system for health care data (data transparency). Available from: https://www.dimdi.de/dynamic/en/ further-services/health-care-data/. Accessed April 7, 2019.
22. The Federal Institute for Research on Building Urban Affairs and Spatial Development. District reform in MecklenburgWestern Pomerania; 2011. Available from: https://www.bbsr.bund. de/BBSR/DE/Raumbeobachtung/Raumabgrenzungen/deutschland/ kreisgebietsreformen/KreisreformMeckPomm.html. Accessed May $17,2019$.

23. Böger R, Schmidt G. Analgetika. In: Schwabe U, Paffrath D, editors. Arzneiverordnungs-Report 2011. Berlin, Heidelberg: Springer Berlin Heidelberg; 2011:261-278.

24. The Federal Institute for Research on Building Urban Affairs and Spatial Development. Location indicator 2010. Available from: https://www.bbsr.bund.de/BBSR/DE/Raumbeobachtung/Downloads/ downloads_node.html. Accessed September 1, 2020.

25. Kühn M. Peripherien in der räumlichen Planung und Politik. In: Kühn M, editor. Peripherisierung und Stadt. Bielefeld: transcript Verlag; 2016:41-58. [Book in German]

26. Paulozzi LJ, Mack KA, Hockenberry JM. Variation among states in prescribing of opioid pain relievers and benzodiazepines - United States, 2012. J Safety Res. 2014;51:125-129. doi:10.1016/j. jsr.2014.09.001

27. Todd A, Akhter N, Cairns JM, et al. The pain divide: a cross-sectional analysis of chronic pain prevalence, pain intensity and opioid utilisation in England. BMJ Open. 2018;8(7):e023391. doi:10.1136/bmjopen-2018-023391

28. Möller J, Laflamme L, Söderberg Löfdal K. CYP2D6-inhibiting drugs and the increased risk of fall-related injuries due to newly initiated opioid treatment - A Swedish, register-based case-crossover study. Basic Clin Pharmacol Toxicol. 2015;116 (2):134-139. doi:10.1111/bcpt.12289

29. Brouquet A, Cudennec T, Benoist S, et al. Impaired mobility, ASA status and administration of tramadol are risk factors for postoperative delirium in patients aged 75 years or more after major abdominal surgery. Ann Surg. 2010;251(4):759-765. doi:10.1097/ SLA.0b013e3181c1cfc9

30. Radbruch L, Glaeske G, Grond S, et al. Topical review on the abuse and misuse potential of tramadol and tilidine in Germany. Subst Abus. 2013;34:313-320. doi:10.1080/08897077.2012.735216

31. Garbe E, Jobski K, Schmid U. Utilisation of transdermal fentanyl in Germany from 2004 to 2006. Pharmacoepidemiol Drug Saf. 2012;21:191-198. doi:10.1002/pds.2164

32. Kenan K, Mack K, Paulozzi L. Trends in prescriptions for oxycodone and other commonly used opioids in the United States, 2000-2010. Open Med. 2012;6:e41-7.

33. Sears JM, Edmonds AT, Fulton-Kehoe D. Tracking Opioid Prescribing Metrics in Washington State (2012-2017): differences by County-Level Urban-Rural and Economic Distress Classifications. J Rural Health. 2019. doi:10.1111/jrh.12400

34. Casser HR, Schaible HG. Musculoskeletal Pain. Schmerz; 2015. doi:10.1007/s00482-015-0046-9

35. Kuntz B, Hoebel J, Fuchs J, et al. Social inequalities in the prevalence of chronic back pain among adults in Germany. Bundesgesundheitsblatt Gesundheitsforsch - Gesundheitsschutz. 2017;60(7):783-791. doi:10.1007/s00103-017-2568-z

36. Gebauer S, Salas J, Scherrer JF. Neighborhood socioeconomic status and receipt of opioid medication for new back pain diagnosis. $J \mathrm{Am}$ Board Fam Med. 2017;30(6):775-783. doi:10.3122/ jabfm.2017.06.170061

37. Kroll LE, Schumann M, Hoebel J, Lampert T. Regional health differences - developing a socioeconomic deprivation index for Germany. J Heath Monit. 2017;2. doi:10.17886/RKI-GBE-2017035.2.

38. BKK Dachverband BKK Gesundheits report 2013. Available from: https://www.bkk-dachverband.de/fileadmin/publikationen/gesundheits report/fruehere_gesundheitsreporte/BKK-Gesundheitsreport_2013.pdf. Accessed January 5, 2020. 
39. Grobe T, Steinmann S, Szecsenyi J. Barmer GEK Arztreport 2016; 2016. Available from: https://www.barmer.de/blob/36738/ 41528a9e5704bb8d47e25e00707af4ba/data/pdf-arztreport-2016.pdf. Accessed January 5, 2020.

40. Kemper C, Sauer K, Glaeske G. BARMER GEK Heil- und Hilfsmittelreport 2012; 2012. Available from: https://www.barmer. de/blob/36980/b7f25ab2fc736e79e68385c5a7064807/data/pdf-reportheil-und-hilfsmittel-2012.pdf. Accessed January 5, 2020.

41. Wissenschaftliches Institut der AOK (WIdO). Heilmittelreport 2011; 2012. Available from: https://www.wido.de/fileadmin/Dateien/ Dokumente/Publikationen Produkte/Buchreihen/Heilmittelbericht/ wido_hei_hmb_2011.pdf. Accessed January 3, 2020.
42. Schnell M, Currie J. Addressing the opioid epidemic: is there a role for physician education? Am J Health Econ. 2018;4(3):383-410. doi:10.1162/ajhe_a_00113

43. Hoffmann F, Icks A. Structural differences between health insurance funds and their impact on health services research: results from the Bertelsmann Health-Care Monitor. Gesundheitswesen. 2012;74. doi:10.1055/s-0031-1275711.

44. Hoffmann F, Koller D. Different Regions, Differently Insured Populations? Socio-demographic and Health-related Differences Between Insurance Funds. Gesundheitswesen. 2017;79. doi:10.1055/ s-0035-1564074.

\section{Publish your work in this journal}

The Journal of Pain Research is an international, peer reviewed, open access, online journal that welcomes laboratory and clinical findings in the fields of pain research and the prevention and management of pain. Original research, reviews, symposium reports, hypothesis formation and commentaries are all considered for publication. The manuscript management system is completely online and includes a very quick and fair peer-review system, which is all easy to use. Visit http:// www.dovepress.com/testimonials.php to read real quotes from published authors. 